\title{
Acetabular Labral and Chondral Pathology
}

\author{
Alexandros Tzaveas ${ }^{*}$ and Richard Villar
}

The Richard Villar Practice, The Wellington Hospital, London, UK

\begin{abstract}
Acetabular labral and chondral pathology is a very frequent finding during hip surgery and is believed to be responsible for persistent hip pain after sports injuries. The acetabular cartilage and labrum form a complex anatomical structure which provides the appropriate biomechanical features for a harmonic movement between the femoral and acetabular bones. Any factor (structural or acquired) that distorts this anatomy can potentially be a cause of hip pain and can subsequently lead to structural changes of the articular cartilage. The diagnosis of acetabular and chondral pathology is a challenging procedure which necessitates an excellent clinical examination and the use of both classical and advanced radiological investigations. Hip arthroscopy rendered the method of choice as a minimal invasive technique to deal with hip pathology. A long rehabilitation program is required to ensure the return of an athlete to his previous sports activities.
\end{abstract}

Keywords: Labrum, acetabular cartilage, hip arthroplasty, hip, groin.

\section{INTRODUCTION}

Acetabular labral and chondral pathology of the hip joint has become widely known to the orthopaedic community over the last ten years [1]. The management of a painful hip in an athletic adult being treated as a "hip sprain", "idiopathic hip pain" or "early osteoarthritis" was not an uncommon practice 20 years ago. However, the improvement in imaging techniques, mainly MRI with or without arthrography, has led to a better understanding of hip pathology [2]. More recently, hip arthroscopy has made a major contribution not only to the confirmation of MRI findings, but also to the appreciation of the configuration and classification of lesions of the hip joint.

Labral and chondral pathology are frequent findings in patients with a painful hip. One study showed that of 328 patients who underwent arthroscopy for hip pain, 93 (28.35\%) were found having a labral tear or osteochondral defect [3]. It seems that labral tears and chondral pathology are linked, as both appear to occur in the same zone of the acetabulum in $94 \%$ of patients [4]. This suggests a strong connection between labral pathology and subsequent degenerative changes.

This article aims to review all aspects of labral pathology and associated chondral damage, with an emphasis to sports injuries.

\section{ANATOMICAL CONSIDERATIONS}

\section{Macroscopic Features}

Macroscopically, the acetabular labrum appears as an extension of the acetabular cartilage, creating an overcoverage of the femoral head. It is a continuous structure around the acetabulum and forms the transverse acetabular ligament inferiorly [5]. Typically, it has a triangular shape,

*Address correspondence to this author at the Richard Villar Practice, The Wellington Hospital, London, UK; Tel: +4474835148; Fax: +44-20748352

71; E-mail: Tzaveas@hotmail.com with the base attached to the acetabular cartilage and bony rim, and the apex being free. Kelly et al. [6] divided the labrum into two zones, the articular-side, adjacent to the femoral head, and the capsular-side, adjacent to the periacetabular sulcus, which is formed between the labrum and the joint capsule. The bony attachment is such that the osseous acetabulum extends into the substance of the labrum [5].

When inspected arthroscopically, the shape of the labrum is not always triangular but can be rounded, flattened or irregular. There is also, a significant difference between its anterior and posterior portions, the anterior being wider and thinner, and the posterior thicker and narrower. A sulcus between posterior labrum and acetabular cartilage is a frequent finding, the labral groove, and may be erroneously perceived as pathological. Another variation, the bifid labrum, can also give the impression of a posterior labral tear [7].

\section{Histology}

The labrum has a fibrocartilaginous structure. A histological study in term fetuses [8] showed it to comprise thick, dense bundles of collagenous fibres, resembling a ligament in appearance; chondrocytes have been observed at the inner articular surface of the socket, whereas fibrocytes were found in the substance of the labrum, between the collagen bundles.

The acetabular labrum was studied extensively by Seldes et al. [5] who reported on its histological features and vascularity. They found that the labrum was integrated into the acetabular articular cartilage through a transitional zone of 1 to $2 \mathrm{~mm}$. They also found a consistent thin bony extension from the edge of the bony acetabulum into the substance of the labrum. The labrum was firmly attached to that bony extension on its articular side via a zone of calcified cartilage, and directly attached to the outer surface of the bone without the interposition of cartilage. The authors also located three to four small blood vessels in the substance of the labrum, travelling circumferentially in the 
substance of labrum, at the area of its attachment to the bone. Furthermore, proprioceptors have been identified in the substance of labrum [9], which are believed to be responsible for proprioception, pain and pressure sense.

\section{Embryology}

A recent embryological study by Cashin et al. [10] improved the understanding of the microscopic anatomy of the labrum. The authors compared the anterior and posterior labrum and found the anterior chondrolabral junction to have an abrupt transition area and a marginal attachment to the articular cartilage. In contrast, posteriorly there was a gradual and interlocked transition, the labrum being directly attached to, and continuous with the acetabular articular cartilage. An interesting finding was the orientation of the collagen fibres, which were parallel to the chondrolabral junction anteriorly but perpendicular posteriorly. The authors attributed the high frequency of anterior labral tears, in contrast with posterior tears, to these findings.

\section{BIOMECHANICAL PROPERTIES}

The significance of the labrum to the stability of the human hip joint was mentioned as early as 1837, when Weber and Weber conducted experiments on cadavers [11]. The labrum contributes to the stability of the hip joint by having a sealing effect, creating a negative intra-articular pressure on any exertion of forces which could distract the hip. The latter was shown by Takechi, Nagashima and Ito [12] by measuring the pressure inside and outside the labrum with a needle pressure transducer. By using an axisymmetric finite element model, Ferguson et al. [13] showed that the labrum can seal against fluid expression from the joint space, which potentially can protect the cartilage layers of the hip, since the loads applied to the articular surfaces are carried by fluid pressure within the cartilage, limiting the magnitude of stresses within the solid collagenous chondral matrix [14]. The same team [15], using a similar model and by applying and maintaining a vertical load to the femoral component, demonstrated a shifting of the centre of contact between the femoral head and acetabular articular surface towards the acetabular rim and showed that strains and stresses were increased in the absence of labrum, which could have a catastrophic effect on articular cartilage. These authors also claimed that the labrum prevents lateral motion of the femoral head within the acetabulum, preserving joint congruence and stability. In a follow up study, these researchers indicated that hydrostatic fluid pressurisation within the intra-articular space is greater with a labrum than without one [16].

\section{PATHOLOGY: TYPES AND CLASSIFICATION}

Because of their anatomical proximity, the acetabular labrum and articular cartilage are subject to the same forces, injuries or pathological conditions. It is common in clinical practice to identify concurrent pathology in both structures during arthroscopic surgery. However, in many instances unrelated distant lesions may be noticed within the hip. Consequently, the pathology of each structure will be considered separately below.

\section{Labral Pathology}

A labral tear is a common finding in an athlete with persistent hip pain, with or without mechanical symptoms. Labral pathology as a source of hip pain has only been widely recognised relatively recently. However, the first to mention a labral tear after an irreducible posterior hip dislocation was Peterson in 1957 [17], followed by Dameron in 1959 [18]. Altemberg [19] was the first to report two cases of a non-traumatic labral tear, which were treated by open resection of the torn fragments, and Suzuki et al. [20] were the first to publish their experience of observing labral tears arthroscopically in five patients.

According to their location, acetabular labral tears can be classified as anterior, posterior and superior / lateral. The most common location is the anterior portion of labrum, according to the Western literature [21]. It appears that the Japanese population shows a predominance of tears in the posterior labrum, probably because of the frequent practice of squatting or sitting on the ground or floor [22-24].

In terms of aetiology labral tears are classified into traumatic, degenerative, idiopathic and congenital [25]. Traumatic tears are those with a clear history of hip injury but with no arthroscopic evidence of degenerative change within either the labrum or articular cartilage. Degenerative tears are those with concurrent degenerative changes within the labrum or articular cartilage. Patients with idiopathic tears have no history of injury, and no arthroscopically identifiable degenerative change. Congenital tears are regarded as being tears in labral instability.

Labral tears may also be classified according to their arthroscopic morphology into radial flap, involving the free margin of the labrum with the formation of a discrete flap, radial fibrillated, with a hairy appearance at the free margin of the labrum, longitudinal peripheral, along the acetabular insertion of the labrum and unstable, which is a reflection of abnormal labral function (Fig. 1) [25]. McCarthy et al. [26] described a separate bucket handle-type lesion, in which the labrum separates from the acetabular rim at the chondrolabral junction.

From the histological point of view there are two kinds of acetabular labral tear, type 1 and type 2 [5]. Type 1 is a tear where there is a detachment of the labrum from the chondral surface, at the transition zone between fibrocartilaginous labrum and the hyaline articular cartilage. This tear is perpendicular to the articular surface and, occasionally, extends down to the subchondral bone. In type 2 tears there are one or more cleavage planes of variable depth within the substance of the labrum, extending perpendicular to the surface of the labrum. When extending to the subchondral bone, the tears of this type are associated with tidemark reduplication and endochondral ossification in the labrum.

\section{Acetabular Chondral Pathology}

Chondral pathology may be diffuse, as part of a degenerative process in the joint, or isolated, usually accompanying labral pathology. However, it seems that labral pathology has a link with osteoarthritis [27]; hence, in 


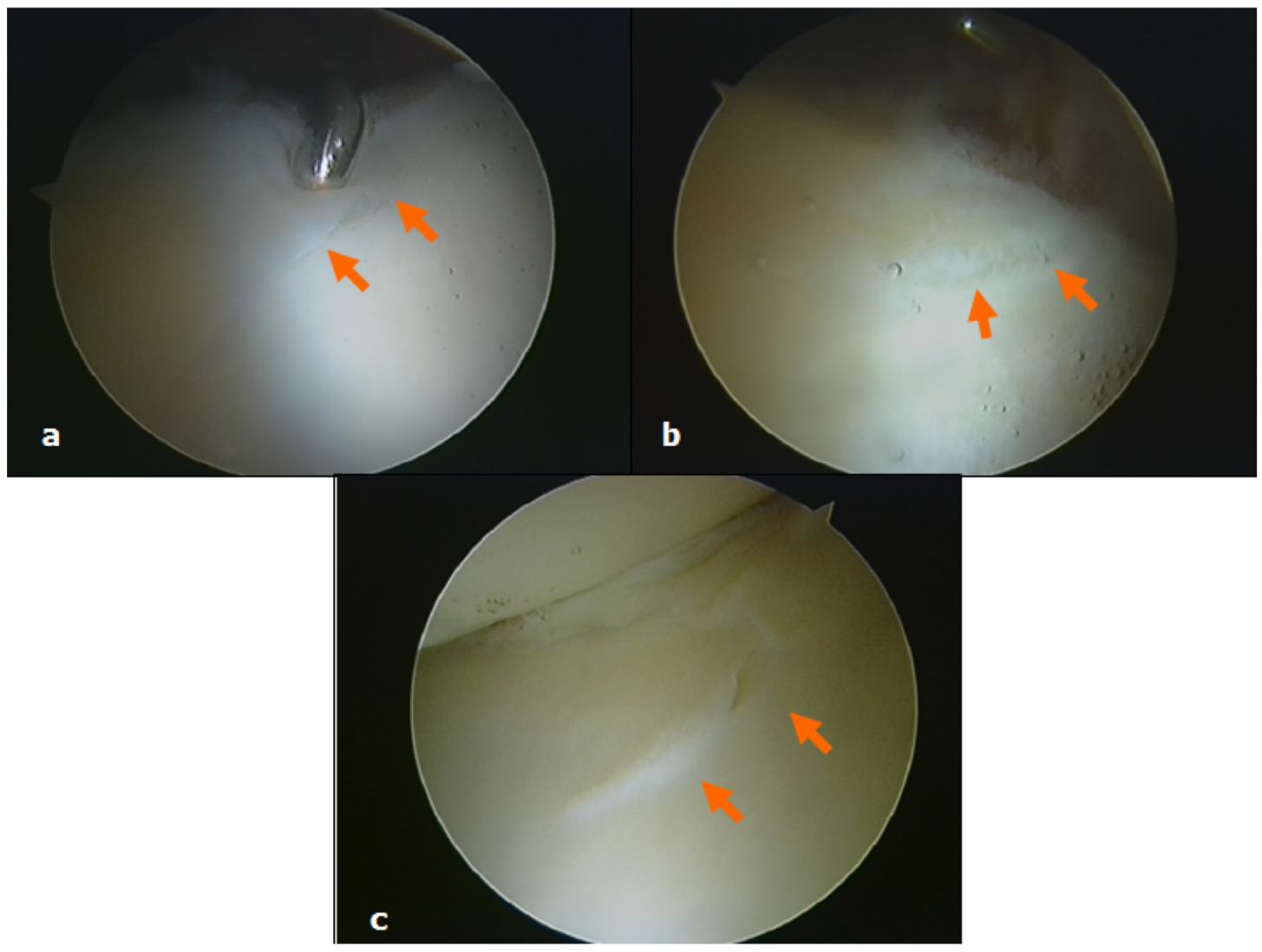

Fig. (1). Types of labral tears (arrows): (a) longitudinal peripheral, (b) radial fibrillated, (c) radial flap.

many instances it is difficult to differentiate between early osteoarthritis and isolated chondrolabral pathology.

Chondral pathology is traditionally described by the use of the Outerbridge classification [28]. Grade I describes softening and swelling of the articular cartilage, grade 2 shows fragmentation and fissuring in an area half-an-inch or less in diameter, grade 3 the same as grade 2 but an area of more than half -an-inch in diameter involved, and grade 4 describes erosion of cartilage down to bone. However, Outerbridge used this classification system to describe chondral lesions on the retropatellar articular surface; this system is not always sufficient to describe acetabular articular cartilage deficiencies, which may have different configuration. The classification of Beck et al. [29] is perhaps more descriptive and takes into account the particularities of acetabular articular cartilage damage (Table 1). Perhaps the most important difference between these two classification systems is Stage 3 of the Beck et al. classification, which is arthroscopically seen as the "wave sign" (Fig. 2) [30]. Here, pressure applied to the rim of the acetabular labrum during hip arthroscopy will cause bulging of the adjacent articular cartilage.

\section{AETIOLOGY}

As new information is continuously added to the pathological entity of the so-called young non-arthritic hip, it is difficult to identify the primary contributing factors for labral and chondral pathology. That said, femoroacetabular impingement, a relatively new concept, seems to be responsible for many cases with labral or chondral damage. Meanwhile, the traditional classification of the morphology of labral tears by Lager et al. seems to be inadequate.

Trauma, in the form of an obvious acute major hip injury was primarily thought to be the main reason for labral tears $[17,18]$. It is now known that repetitive minor trauma, especially in athletes, may have the same effect. Sports such

Table 1. Beck et al. Classification System for Cartilage Damage

\begin{tabular}{|c|c|c|}
\hline Stage & Description & Criteria \\
\hline \hline 0 & Normal & Macroscopically sound cartilage \\
\hline 1 & Malacia & Roughening of surface, fibrillation \\
\hline 2 & Pitting malacia & Roughening, partially thinning and full-thickness defects or deep fissuring to the bone \\
\hline 3 & Debonding & Loss of fixation to the subchondral bone, macroscopically sound cartilage; carpet phenomenon \\
\hline 4 & Cleavage & Loss of fixation to the subchondral bone; frayed edges, thinning of the cartilage \\
\hline 5 & Defect & Full-thickness defect \\
\hline
\end{tabular}


as soccer, hockey, golf, martial arts and ballet involve continuous movements of hyperabduction, hyperextension, hyperflexion and external rotation, all of which have been implicated as causing labral damage [31]. The incidence of this injury is even higher in elite athletes. Hyperextension combined with femoral external rotation is considered as the injury pattern most commonly associated with the acute presentation of acetabular labral tears [32]. By this movement most of the forces are transmitted through the labrum on weight-bearing, thus creating the labral tear. Bharam [33] reported that the most commonly associated lesion with a labral tear in athletes were chondral injuries of the neighbouring area to the labral tear.

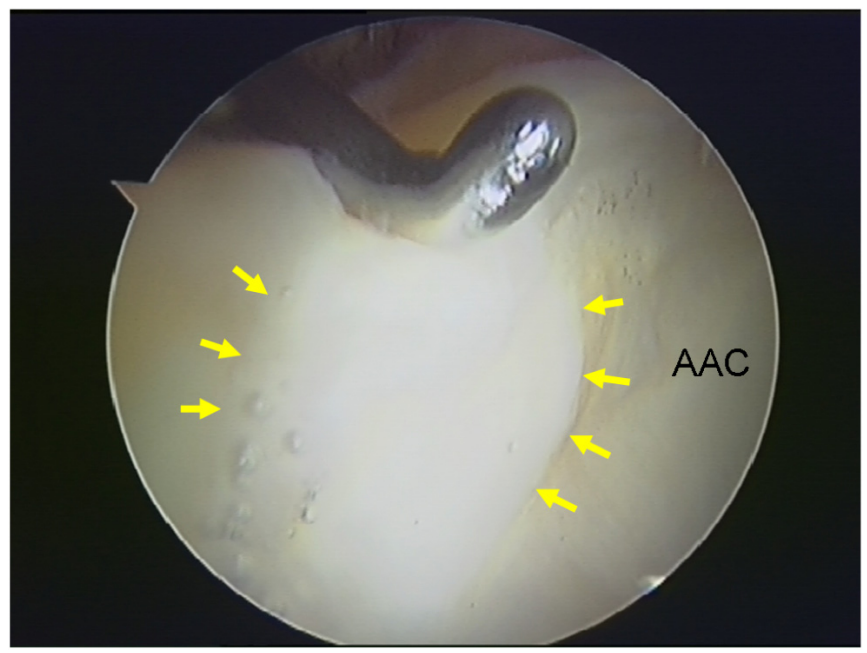

Fig. (2). Arthroscopic view of delaminated acetabular articular cartilage (AAC); pressure on the adjacent labrum with the hook creates a bulging of the cartilage (yellow arrows), the so-called "wave sign".

Congenital hip dysplasia has been always considered a predisposing factor for labral tears [20,34]. Haene, Bradley and Villar [35] found dysplasia in $46 \%$ of patients with arthroscopically-diagnosed acetabular labral tears. An association has been shown with acetabular dysplasia, defined as a centre-edge angle lower than $25^{\circ}$ and a Tonnis angle greater than $10^{\circ}$ [36-38]. It is thought that in this population a hypertrophic labrum exists, which is caught between the femoral head and acetabular margin, thereby causing mechanical symptoms and pain.

Degenerative labral tears are very common in an aging population, especially those over 60 years old [26]. It is not yet clear, whether a labral tear causes degeneration of the joint, or whether it is part of the ageing process itself.

However, perhaps the most interesting aetiological group is that containing labral tears caused by the femoroacetabular impingement lesion (FAI). This is an abutment between the proximal femur and the acetabular rim [1]. There are three types of FAI, 1) cam, in which the source of impingement is a non-spherical femoral head, 2) pincer, in which there is overcoverage of the femoral head by the acetabulum, and 3) mixed, which is a combination of cam and pincer. It is commonly found in young and athletic adults. The cam lesion is characterised by an abnormal osteocartilaginous prominence located at the anterolateral femoral head-neck junction, and can be caused by a slipped capital femoral epiphysis, femoral head avascular necrosis and flattening, previous femoral neck fracture, Legg-Perthes-Calvé disease, an elliptical femoral head, decreased femoral anteversion or abnormal separation of the proximal femoral epiphysis. A pincer lesion is the result of acetabular retroversion, coxa profunda, protrusio acetabuli, coxa vara, or may develop after reconstructive osteotomy or trauma. It has been shown that this pathological entity can cause a labral tear, consequent acetabular chondral damage and osteoarthritic change [27, 39].

\section{SYMPTOMATOLOGY AND CLINICAL SIGNS}

The typical patient with a labral tear complains of groin pain which may radiate to the adductor region; occasionally it is referred to the lateral hip area or over the buttock. Rarely does it radiate to the knee. The pain is activity-related and becomes worse during sport activities. In general this condition prevents very active patients from doing sports. Many patients refer to a period of one or two days with increased groin pain after strenuous activities. Occasionally the symptoms worsen after prolonged periods of sitting. The onset is usually insidious, although can be acute in some patients. Other symptoms include clicking, snapping, catching or giving way.

The differential diagnosis is multiple but may include osteitis pubis, arthropathy of the hip, synovial osteochondromatosis, saphena varix, stress fracture, avascular necrosis, obturator externus injury, neoplasia, transient osteoporosis, inguinal hernia, Gilmore's groin [40] or even simple hip sprain. Diagnosis is rarely instant.

On examination patients may present with a normal or Trendeleburg gait, depending on the severity of symptoms. In most cases the range of hip movement is within the normal range. The most frequently positive clinical maneouvre is the impingement sign [41], reproduced by flexing the hip to $90^{\circ}$, while adducting and internally rotating the joint; this causes groin pain. In cases with posteroinferior impingement the FABER test (flexion, abduction and external rotation) is positive. This is shown by an increased distance between the lateral aspect of the knee and the examination couch, during the test, when compared with the normal, contralateral side. It is generally difficult to differentiate clinically between an anterior and a posterior labral tear. However, Fitzgerald [42] described a clinical maneouvre for testing the anterior and posterior labrum: pain with or without clicking induced by acute flexion, external rotation and full abduction and then extension with internal rotation and adduction implied an anterior labral tear; meanwhile, extension with abduction and external rotation from the fully flexed, adducted and internally rotated position reproduced pain with or without clicking in the presence of a posterior labral tear. It is worth remembering that, even for an experienced hip surgeon, the clinical diagnosis of a labral tear and particularly the differentiation between anterior or posterior pathology, is challenging.

\section{IMAGING}

A complete radiographic evaluation should always begin with plain radiographs of the hips, including anteroposterior and lateral views. Albeit not diagnostic for labral or chondral pathology, these give the opportunity to note any osseous abnormalities or hip dysplasia. In cam FAI anteroposterior 
radiographs usually reveal a flattened head-neck junction of the proximal femur, the so-called "pistol-grip" deformity (Fig. 3). In pincer FAI (Fig. 4) there is overcoverage of the femoral head by the acetabulum. A cam deformity can be measured by the $\alpha$-angle [43] and head-neck offset [43], while pincer impingement is suggested by a cross-over sign [44]. Acetabular retroversion is suggested by the presence of a posterior wall sign [45] or ischial sign [46]. Coxa profunda [47] and protrusio acetabuli [48] should be excluded. The angle of Wiberg [49] is used for the assessment for acetabular dysplasia.

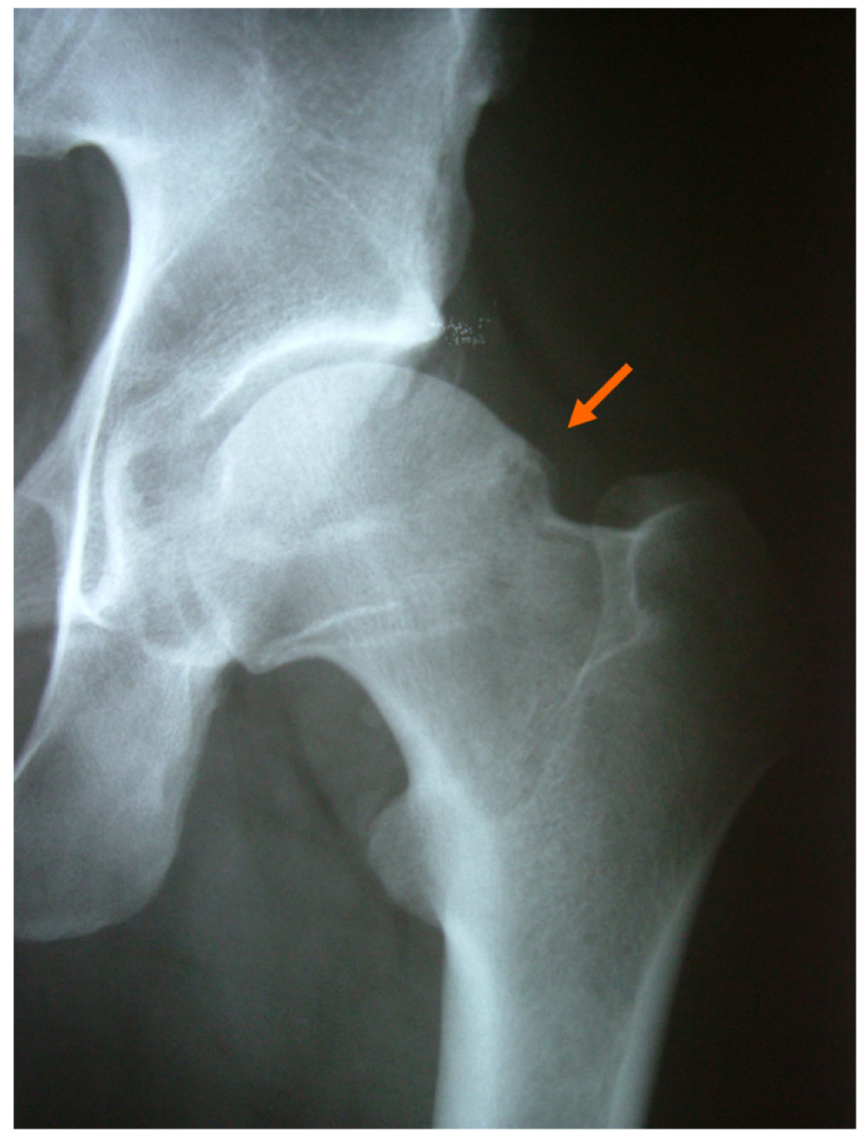

Fig. (3). The cam impingement lesion at the head-neck junction (arrow).

Magnetic resonance imaging (MRI) is probably the best modality for suspected occult fracture, transient marrow oedema and avascular necrosis in the hip. MRI also helps to exclude other abnormalities such as neoplasia, osteitis pubis, synovitis and extra-articular soft tissue problems. Unfortunately, its reliability for diagnosing labral tears is not guaranteed, as it produces both false-positive and falsenegative results for labral pathology. Czerny et al. [50] studied the sensitivity and accuracy of MRI for labral tears in 22 labra compared with MR arthrography, and found it to be $30 \%$ and $36 \%$, respectively. Edwards, Lomas and Villar [51] compared the findings of MRI with those of hip arthroscopy in 23 young adults with hip pain and found that labral tears and osteochondral loose bodies were not well demonstrated by MRI. The main limiting factor appears to be the lack of joint distension and the joint capsule collapse against the acetabular rim [52]. Toomayan et al. [53] found an $8 \%$ sensitivity in detecting labral tears with conventional MRI at a large field view and $25 \%$ with a small field of view.

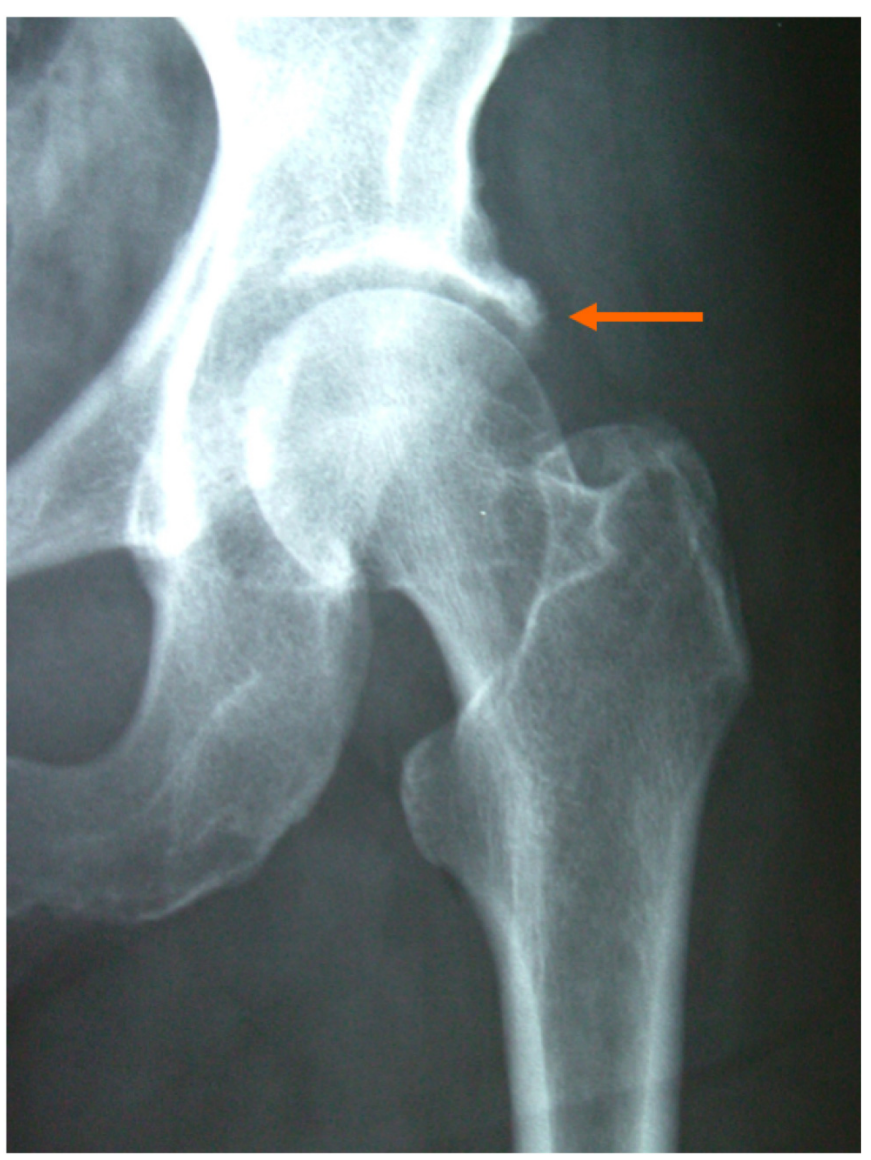

Fig. (4). Pincer lesion (arrow) with overcoverage of the femoral head.

Magnetic resonance arthrography (MRA) is the modality of choice for assessment of intrarticular pathology, including labral tears. It combines the advantages of MRI with the distension of joint by the intrarticular injection of gadolinium. By distending the joint, the labrum is separated from the capsule, creating a conspicuous appearance of all intrarticular structures. Furthermore, gadolinium enters the gaps of the tears and outlines labral pathology. The sensitivity of MRA in detecting labral tears has been shown to be reasonably high. Czerny et al. [50] found the sensitivity and accuracy of MRA for labral tears to be $90 \%$ and $91 \%$, respectively. Chan et al. [54] compared the MRA and arthroscopic findings in 17 patients, and showed a sensitivity and accuracy of radial reformatted MRA to be from $96 \%$ to $100 \%$. Toomayan et al. [53] found the sensitivity to be $92 \%$ in 51 hips and Freedman et al. [55] showed it to be $96 \%$ in 23 patients.

The normal labrum appears as a black structure on MRI scans, having a uniformly very low signal intensity [52]. It measures $3 \mathrm{~mm}$ to $11 \mathrm{~mm}$ in width and $2 \mathrm{~mm}$ to $5 \mathrm{~mm}$ in height [56] and appears with a triangular shape on coronal or axial images [57]. Labral tears appear as a linear extension of high signal intensity gadolinium solution into the labrum (Fig. 5), labral blunting or detachment of the labrum from the underlying bone; labral cysts may accompany the tears. The most frequent area for labral tears is the anterior labrum; less frequently the superior, and rarely the posterior. In cases with labral degeneration there is an abnormal intermediate (grey) signal within the labrum, but the labral contour is 
preserved and no gadolinium is seen entering the substance of the labrum itself (Fig. 6) [52]. MRA also helps evaluate the articular cartilage, by outlining the articular margins. Normal hyaline cartilage demonstrates an intermediate to bright signal [52]. MRA also helps to define any cartilage defects, subchondral cysts or osteochondral loose bodies. Findings that can be misdiagnosed as labral tears are the sublabral sulcus (or labral groove) [58], cartilage undercutting the labrum, the iliopsoas tendon as it crosses over the anterior labrum [53], an anteroinferior cleft at the junction between the labrum and the transverse ligament and increased signal intensity at the chondrolabral junction [59].

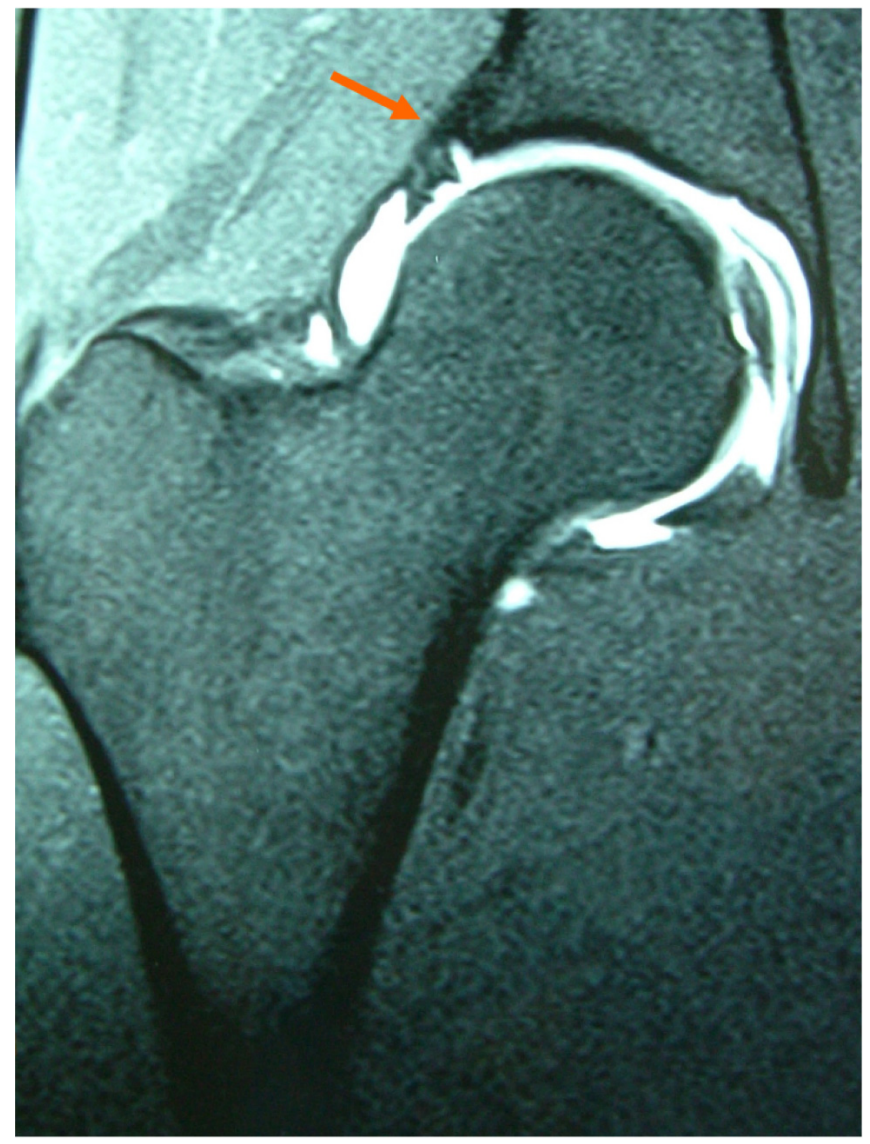

Fig. (5). MRI arthrogram of the right hip showing an obvious separation of the labrum form acetabular rim (arrow) indicated by the linear extension of high signal intensity gadolinium solution.

\section{TREATMENT}

All patients with hip pain, with or without history of trauma, should be treated conservatively at first unless there is strong indication to the contrary. However, clinicians must have a high index of suspicion for the possibility of a labral tear, which is sometimes diagnosed many months after the onset of symptoms, and patient is then unable to recall any traumatic event.

Conservative treatment includes rest, non-steroid antiinflammatory drugs and physiotherapy. Unfortunately little data are available regarding the efficiency of conservative treatment; there are indications that rest and physiotherapy alleviate symptoms, but as the patient returns to physical activities so the symptoms may recur. This has been attributed to the assumed low ability of a labrum to heal alone, as applies to the non-vascularised part of the knee meniscus [60], without the aid of surgery. Physical treatment is not recommended by some authors [61]. Others believe that physiotherapy may improve the pattern of gait and muscle balance, which helps to alleviate symptoms, or to prepare patient for a forthcoming operation. Lewis and Sahrmann [62] have proposed a physiotherapy protocol for muscle strength and modifications of functional activities; they believe that the optimisation of the alignment of the hip joint and the precision of passive and active joint motion, by correcting the movement patterns and avoiding pivoting motion, can reduce anterior hip pain before, or in the absence of, surgery. Fitzgerald [42] found conservative treatment to be effective in seven out of 55 patients. Ikeda et al. [22] found protected weight-bearing to improve symptoms in six out of seven patients, and Hase and Ueo [23] found the conservative treatment unsuccessful in two patients. In our own experience, patients with a more than three-month history of hip pain, and radiographic indication of a labral tear, are unlikely to improve unless they avoid their previous sporting activities. The natural history of the lesion is that of worsening of symptoms whenever the patient tries to be more active. Clearly, the threshold at which surgery is offered to a professional athlete will be lower than that for a more sedentary patient.

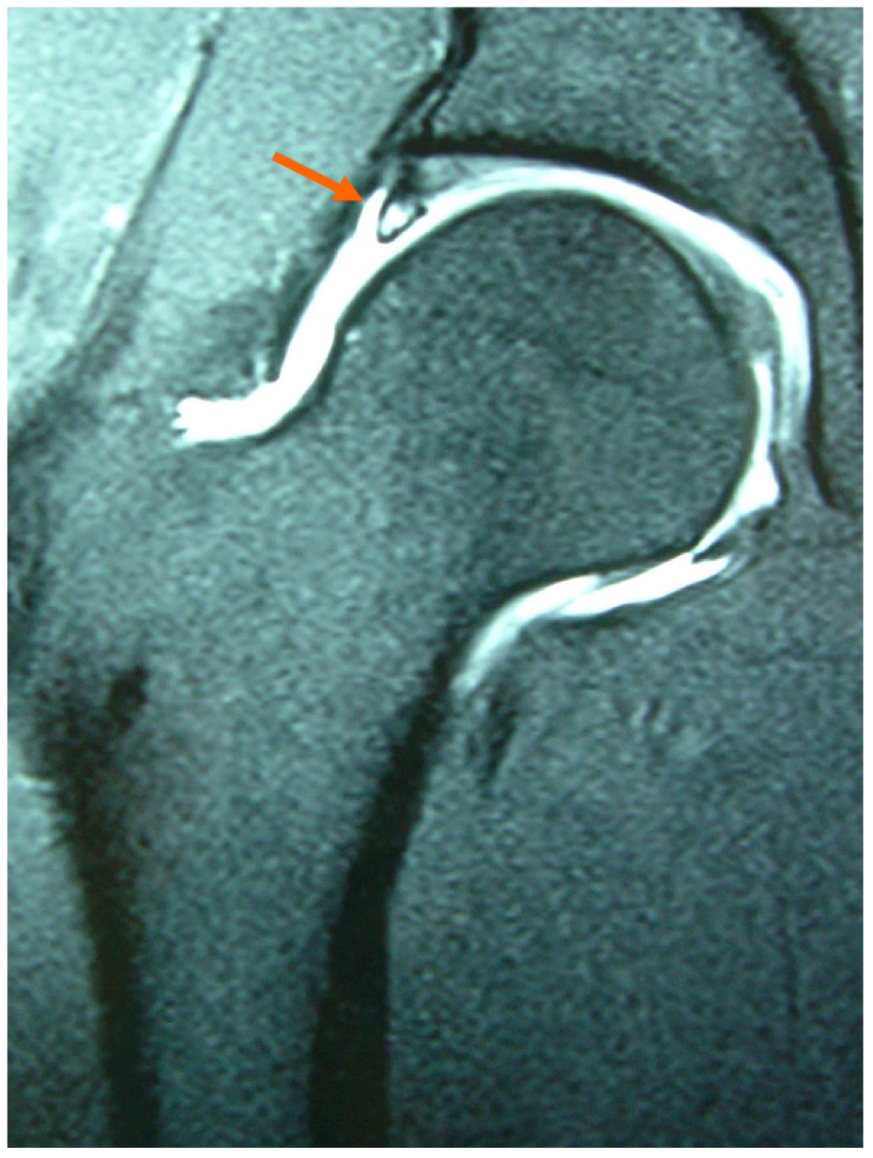

Fig. (6). MRI arthrogram of the right hip showing a degenerative labrum, indicated by the grey signal within the substance of the labrum (arrow).

Open surgery has been used for patients with hip pain, cam femoroacetabular impingement and suspected labral pathology. The aim has been the trimming of the impingement lesion at the head-neck junction of the femur 
and treatment of the torn labrum. Smith-Petersen was the first ever to describe the technique as early as in 1936 [63]. More recently, Ganz et al. [64] used this technique extensively and gave a new perspective to the surgical management of the painful non-arthritic hip. Espinosa et al. [65] published their work on open arthrotomy and excision of the cam lesion in 60 hips, and found that the group with concurrent labral refixation recovered earlier, and had superior clinical and radiographic results, than patients who had undergone resection alone of a torn labrum. However, the demand for minimally invasive surgery for these problems, the avoidance of morbidity related to arthrotomy and hip dislocation, and the improvement in instruments and distraction techniques, has now rendered hip arthroscopy the gold standard for treating acetabular labral and chondral pathology in many hands.

Hip arthroscopy is the intervention of choice in patients with a suspected torn acetabular labrum or articular cartilage lesions. As a diagnostic method, it can confirm MRI and MRA intra-articular findings, having $100 \%$ sensitivity and specificity. As a therapeutic tool, it can be used for a large number of pathological conditions, like cam or pincer-type impingement lesion, removal of loose bodies, management of osteochondral defects, synovectomy, partial acetabular labrectomy, labral repair and debridement or even repair of the ligamentum teres.

The arthroscopic procedure involves the creation of two to four portals in the area of the hip joint, each about $1 \mathrm{~cm}$ in size. The patient can be placed either in the supine or lateral position, according to the surgeon's preference. The positioning of the patient is one of the critical parts of the operation. To achieve sufficient and safe distraction of the hip requires meticulous use of distraction systems, which will immobilise the patient, stabilise the foot and, at the same time, avoid pressure sores, neurovascular injury and compression on the contralateral limb. The hip joint is arthroscopically divided into two compartments, the central and peripheral. The central contains the weight-bearing areas of the joint, with femoral and acetabular articular surfaces, ligamentum teres, labrum and part of the capsule. The peripheral compartment is the non-weight-bearing area of the joint, containing the non-articular surface of the labrum, the head-neck junction, femoral neck and capsule.

The arthroscopic examination usually starts with inspection of the central compartment by the use of two portals. All structures can be assessed and several procedures can be undertaken for the treatment of labral tears, chondral lesions, torn ligamentum teres, foreign or loose body removal or acetabular recession in the presence of pincertype impingement. The surgeon then accesses the peripheral compartment, either by shifting his instruments over the femoral head, after making an extended capsulotomy, or by creating a further portal. In the peripheral compartment a cam-type impingement lesion can be assessed visually and dynamically, and can be excised. At this stage it is also possible to assess the iliopsoas tendon, although this normally requires penetration of the anterior capsule in order to be adequately exposed.

The method of treatment of a torn labrum depends on the configuration of the tear. Small tears, fibrillated and/or degenerative labra can be treated with simple debridement, either mechanically with a shaver or by ablation, using a radiofrequency probe. Fragments of a larger size can be sutured by the use of arthroscopic sutures. Large flaps may also stabilised to the articular capsule by the use of an arthroscopic suture. A detached labrum can be stabilised with bone anchors, which are inserted to the acetabular osseous rim. Another tool for suturing the labrum is the FastFix (Smith \& Nephew Inc., Endoscopy Division, Andover, Massachusetts) (Fig. 7), which permits a rapid and safe method of suturing soft tissue.

Chondral lesions are treated according to their severity, configuration and extension. Small defects can be treated by microfractures (Fig. 8) [66], which induces the formation of fibrocartilage after the release of multipotent cells from the subchondral bone. Mosaicplasty [67] and autologous chondrocyte transplantation [68] are other promising techniques. Early degenerative changes may be treated with debridement and smoothening, either mechanically or with ablative probes. However, with chondral delamination (Fig. 2) the surgeon faces the dilemma of either removing the unstable articular cartilage, or trying to preserve it. Unpublished data from our practice have shown the efficacy of fibrin in stabilising acetabular cartilage in patients with delamination.

When the underlying cause of labral or chondral pathology is femoroacetabular impingement lesion, then removal of the lesion is an inextricable part of the arthroscopic procedure. If the impingement lesion is of the pincer-type, then an acetabular recession is performed, which is the trimming of the osseous acetabular rim by the use of a burr. This may require detachment of the acetabular labrum, with subsequent reattachment using anchors. However, in certain circumstances it is possible to perform an acetabular recession but without detaching the labrum itself. When there is a cam-type impingement lesion then the arthroscopist should move to the peripheral compartment, which contains the femoral head-neck junction and femoral neck. The excision is, again, performed with an arthroscopic burr; the aim being to remove sufficient bone, to stop the abutment between the femoral head-neck junction and acetabulum (Fig. 9).

\section{REHABILITATION}

Rehabilitation in the first post-operative months is of paramount importance for the outcome of arthroscopic treatment. This can last up to four months before an athlete is able to return to his sporting activities, sometimes longer. Follow-up examination is also crucial for up to one year post-operatively, as the athlete continuously needs consultation, guidance and reassurance during the process of rehabilitation.

As the hip is a deeply-situated joint, covered by a thick layer of soft tissues, the healing process after arthroscopy is relatively slow and needs an intensive physiotherapy protocol. Unfortunately, only sporadic articles regarding this matter can be found in the literature [69].

In our practice the physiotherapy programme begins on the day of operation with simple exercises and mainly educating the patient in the use of crutches. Most patients are 


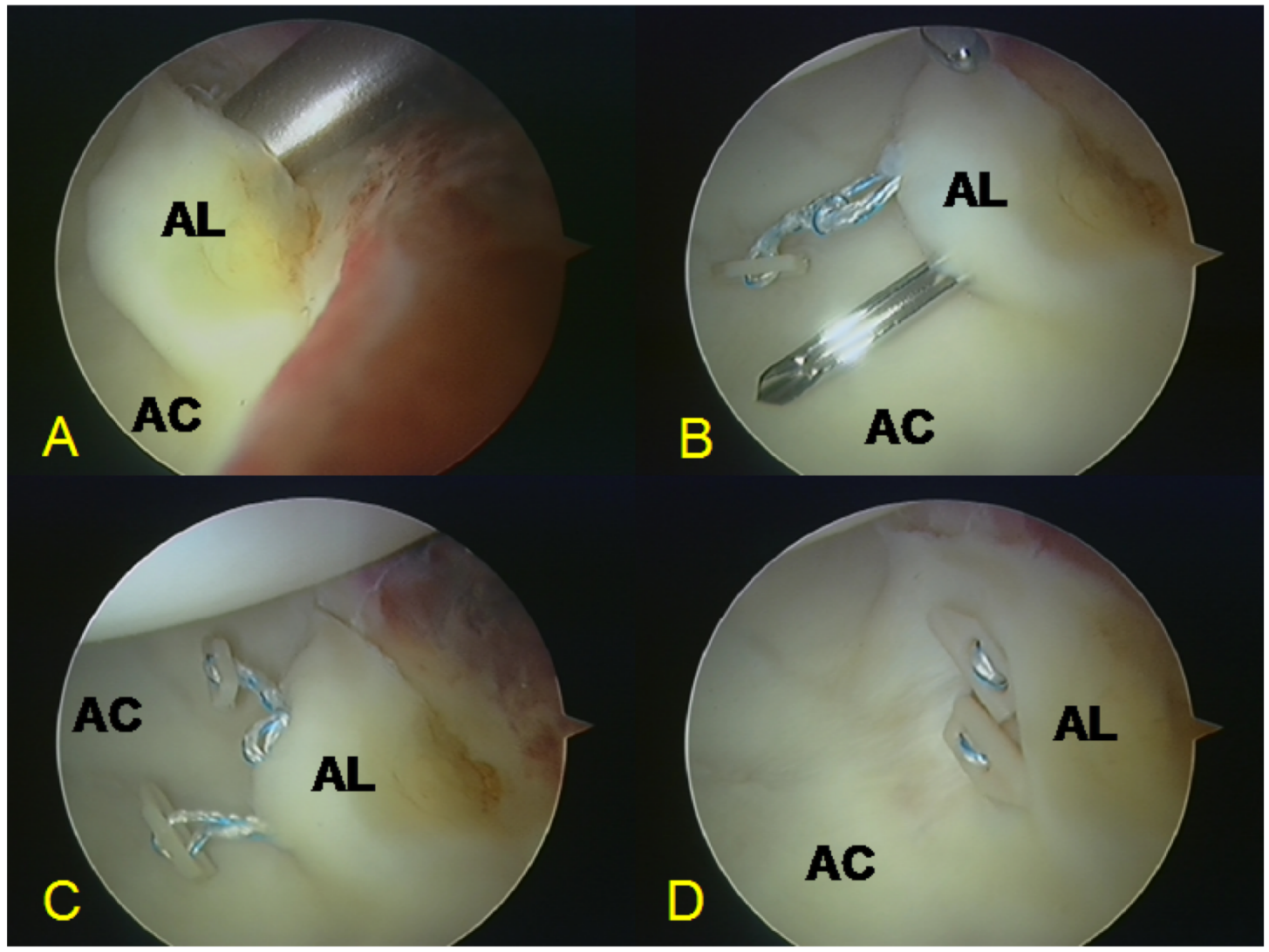

Fig. (7). Labral repair with the FastFix device (Smith \& Nephew Inc., Endoscopy Division, Andover, Massachusetts). (A) Assessment of labral tear with probe, (B) the first loop has been passed, (C) both loops have been placed correctly, (D) tightening of the central loop (not seen) pulls the labrum to its original position (AL: acetabular labrum, AC: acetabular cartilage).

advised to mobilise on crutches touch-weight bearing for a period of four weeks. Patients with excision of an impingement lesion are advised to avoid flexion of more than $90^{\circ}$ for four weeks, to avoid discomfort. Intense physiotherapy begins one week post-operatively. The rehabilitation programmes are generally divided into three categories (simple, intermediate and advanced), according to the complexity of the procedures undertaken; however, the main guidelines remain the same. Gait re-education, isometric and range-of-movement exercises begin from the day of the operation. Stretching of the surrounding muscles begin on the second to fourth week, depending on the complexity of procedures undertaken. Strengthening usually begins on the fourth to sixth week. Hydrotherapy begins when sutures have been removed and wounds are dry. The stationary bicycle is an excellent exercise, which can be adjusted according to patient needs by increasing the saddle height for increased range of movement or adding resistance to improve muscle strengthening. The introduction of highimpact activities and specific sports are mainly decided by consultation with the surgeon, but are usually scheduled for three to four months after the arthroscopic procedure. It is crucial that a rehabilitation programme should be continuously adjusted and discussed during the follow-up, as it frequently needs to be adapted to the patient's specific needs. Patients may be seen in the clinic six weeks, three months and nine months after hip arthroscopy, and every year thereafter.

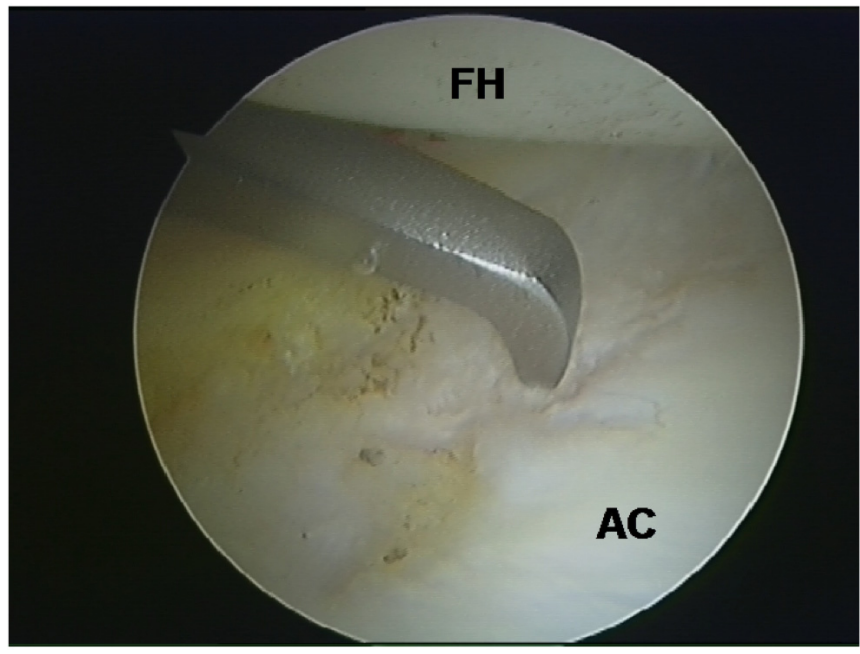

Fig. (8). Microfracture being performed with an arthroscopic microfracture pick (FH: femoral head, AC: acetabular cartilage).

\section{OUTCOMES FROM SURGERY FOR LABRAL TEARS}

Although lacking in prospective, randomised clinical trials, the literature provides sufficient evidence and numerous studies to support surgery for labral damage. Both open and arthroscopic procedures provide pain relief and improve function in appropriately selected patients. 


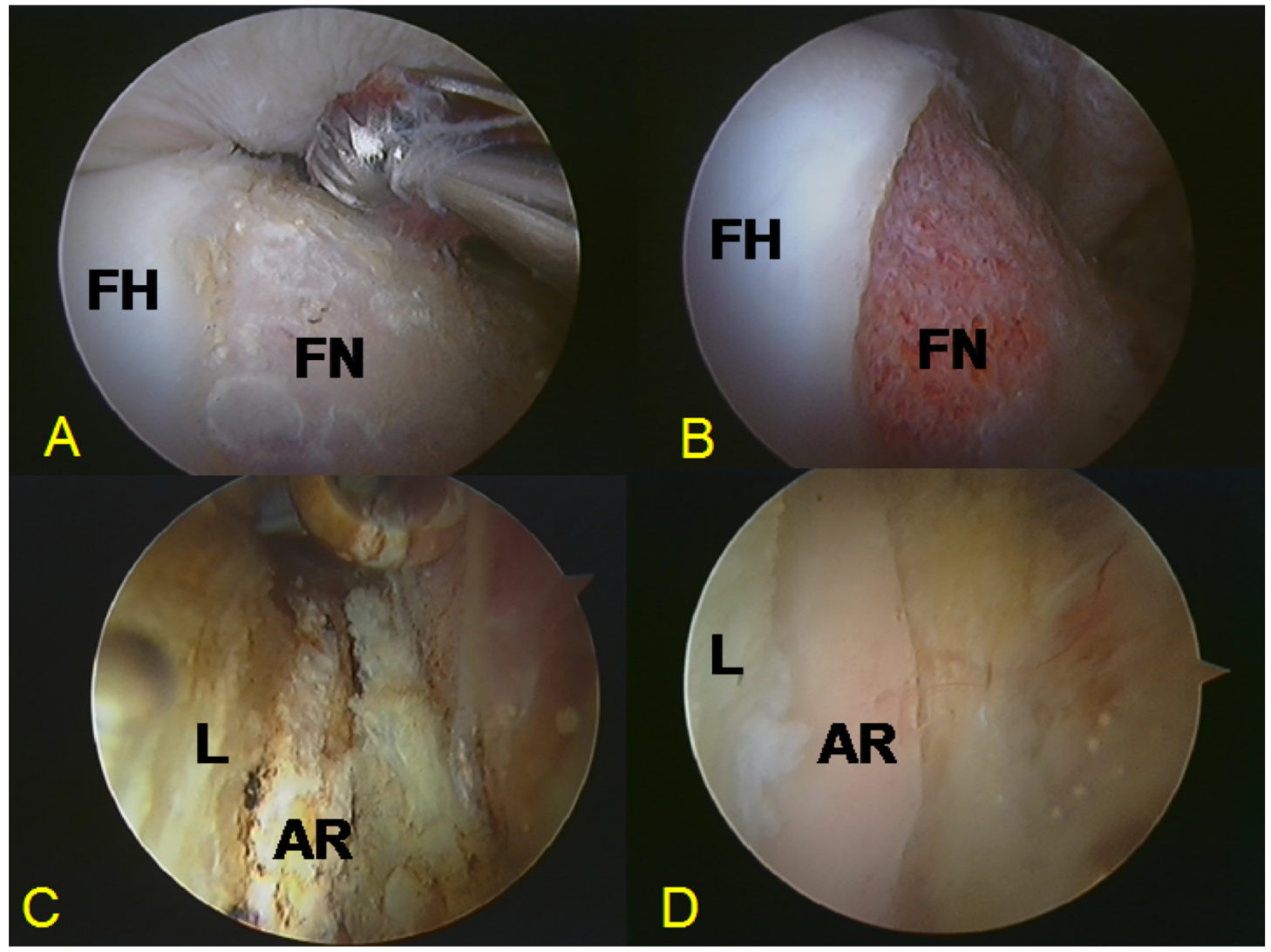

Fig. (9). Arthroscopic excision of an impingement lesion. (A) Cam-type lesion and arthroscopic burr, (B) the area after excision of impingement lesion, (C) pincer lesion, (D) the area after the acetabular recession (FH: femoral head, FN: femoral neck, L: labrum, AR: acetabular rim).

There are a number of studies which evaluate the open treatment of labral tears and femoroacetabular impingement. Beck et al. [29] reported 70\% good to excellent results in 19 hips, following surgical dislocation, osteoplasty and labral debridement, at a mean follow-up of 57 months. Murphy et al. [70], using similar technique had $65 \%$ good to excellent results at a mean follow-up of 60 months. Beaulé, Le Duff and Zaragoza [71] showed $82 \%$ good to excellent results at 36 months, Peters and Erickson [72] 85\% at 32 months, and Espinosa et al. [65], when comparing two groups with labral debridement and labral refixation, found the results to be $76 \%$ and $94 \%$, respectively.

However, the arthroscopic procedure has gained more popularity in recent years, and has also reported favourable results. Unfortunately, not all available papers include the results after femoral head/neck osteoplasty, as the arthroscopic excision of an impingement lesion has only become commonplace in the last five years. Nevertheless, the results are encouraging. Santori and Villar [73] in 58 patients with labral debridement at a mean follow-up of 42 months showed $67 \%$ of patients to have good to excellent results. Potter et al. [74] in a more recent study in 22 hips showed $68 \%$ good to excellent results in non-disability patients and $39 \%$ good to excellent results in patients with disability claims. Farjo, Glick and Sampson [75] had 71\% good to excellent results in non-osteoarthritic patients. O'Leary Berend and Vail [76] had 90\% good to excellent results in 22 hips. Meanwhile, Byrd and Jones [77] reported $93 \%$ good to excellent results in 44 hips. Philippon et al.
[78], by performing labral resection or repair and femoral osteoplasty found that $78 \%$ of 45 patients were still active in professional sports at a mean follow-up of 19 months. A more recent paper by Byrd and Jones [77] reports the tenyear follow-up after hip arthroscopy for labral pathology in 29 patients; the authors noticed $83 \%$ of non-arthritic patients being still improved, whereas $88 \%$ of osteoarthritic patients were converted to total hip arthroplasty at a mean of 63 months after arthroscopy.

A systematic review by Bedi et al. [79] comparing open and arthroscopic techniques for labral repair and osteoplasty, showed that open techniques have similar results to arthroscopic ones. Another systematic review by Robertson et al. [80] supports the efficacy of arthroscopic techniques for symptomatic and functional improvement after labral debridement.

\section{CONCLUSIONS}

Acetabular labral and chondral pathology are frequent intra-operative findings in young and athletic patients with a painful hip. They can be the result of either an isolated obvious severe trauma of the hip joint or repetitive microtrauma in patients with underlying bony anomalies. MR arthrography is the modality of choice for detecting such pathology. Open and arthroscopic methods of treatment seem to provide a satisfactory post-operative result regarding pain and function. The volume of published literature, with new techniques and outcomes, is continually increasing. As instruments and distraction methods develop, arthroscopic 
hip surgery increasingly becomes the preferred surgical procedure.

\section{REFERENCES}

[1] Tzaveas A, Villar R. Arthroscopic treatment of femoroacetabular impingement. Br J Hosp Med (Lond) 2009; 70(2): 84-8.

[2] Chan YS, Lien LC, Hsu HL, et al. Evaluating hip labral tears using magnetic resonance arthrography: a prospective study comparing hip arthroscopy and magnetic resonance arthrography diagnosis. Arthroscopy 2005; 21(10): 1250.

[3] Baber YF, Robinson AH, Villar RN. Is diagnostic arthroscopy of the hip worthwhile? A prospective review of 328 adults investigated for hip pain. J Bone Joint Surg Br 1999; 81(4): 600-3.

[4] McCarthy JC, Noble PC, Schuck MR, Wright J, Lee J. The Otto E. Aufranc Award: the role of labral lesions to development of early degenerative hip disease. Clin Orthop Relat Res 2001; (393): 2537.

[5] Seldes RM, Tan V, Hunt J, Katz M, Winiarsky R, Fitzgerald RH Jr. Anatomy, histologic features, and vascularity of the adult acetabular labrum. Clin Orthop Relat Res 2001; (382): 232-40.

[6] Kelly BT, Shapiro GS, Digiovanni CW, Buly RL, Potter HG, Hannafin JA. Vascularity of the hip labrum: a cadaveric investigation. Arthroscopy 2005; 21(1): 3-11.

[7] Miller R, Villar RN. The bifid posterior labrum: an anatomic variant of the acetabular labrum. Arthroscopy 2009; 25(4): 413-5.

[8] Walker JM. Histological study of the fetal development of the human acetabulum and labrum: significance in congenital hip disease. Yale J Biol Med 1981; 54(4): 255-63

[9] Kim YT, Azuma H. The nerve endings of the acetabular labrum. Clin Orthop Relat Res 1995; (320): 176-81.

[10] Cashin M, Uhthoff H, O'Neill M, Beaulé PE. Embryology of the acetabular labral-chondral complex. J Bone Joint Surg Br 2008; 90(8): 1019-24.

[11] Weber W, Weber E. Uber die Mechanik der Menschlichen Gehwerkzeuge nebst der Beschreibung eines Versuches uber das Herausfallen des Schenkelkopfes aus der Pfanne im lufverdunnten Raum. Annalen Physik Chemie 1837; 40: 1-13.

[12] Takechi H, Nagashima H, Ito S. Intra-articular pressure of the hip joint outside and inside the limbus. Nippon Seikeigeka Gakkai Zasshi 1982; 56(6): 529-36.

[13] Ferguson SJ, Bryant JT, Ganz R, Ito K. The acetabular labrum seal: a poroelastic finite element model. Clin Biomech (Bristol, Avon) 2000; 15(6): 463-8.

[14] Ateshian GA, Wang H. A theoretical solution for the frictionless rolling contact of cylindrical biphasic articular cartilage layers. J Biomech 1995; 28(11): 1341-55.

[15] Ferguson SJ, Bryant JT, Ganz R, Ito K. The influence of the acetabular labrum on hip joint cartilage consolidation: a poroelastic finite element model. J Biomech 2000; 33(8): 953-60.

[16] Ferguson SJ, Bryant JT, Ganz R, Ito K. An in vitro investigation of the acetabular labral seal in hip joint mechanics. J Biomech 2003; 36(2): 171-8.

[17] Peterson I. The torn acetabular labrum: a block to reduction of dislocated hip. J Bone Joint Surg Br 1957; 39: 306-9.

[18] Dameron TB Jr. Bucket-handle tear of acetabular labrum accompanying posterior dislocation of the hip. J Bone Joint Surg Am 1959; 41-A(1): 131-4.

[19] Altenberg AR. Acetabular labrum tears: a cause of hip pain and degenerative arthritis. South Med J 1977; 70(2): 174-5

[20] Suzuki S, Awaya G, Okada Y, Maekawa M, Ikeda T, Tada H. Arthroscopic diagnosis of ruptured acetabular labrum. Acta Orthop Scand 1986; 57(6): 513-5.

[21] Byrd JW. Labral lesions: an elusive source of hip pain case reports and literature review. Arthroscopy 1996; 12: 603-12.

[22] Ikeda T, Awaya G, Suzuki S, Okada Y, Tada H. Torn acetabular labrum in young patients. Arthroscopic diagnosis and management. J Bone Joint Surg Br 1988; 70(1): 13-6.

[23] Hase T, Ueo T. Acetabular labral tear: arthroscopic diagnosis and treatment. Arthroscopy 1999; 15(2): 138-41.

[24] Suenaga E, Noguchi Y, Jingushi S, et al. Relationship between the maximum flexion-internal rotation test and the torn acetabular labrum of a dysplastic hip. J Orthop Sci 2002; 7(1): 26-32.

[25] Lage LA, Patel JV, Villar RN. The acetabular labral tear: an arthroscopic classification. Arthroscopy 1996; 12(3): 269-72.
[26] McCarthy J, Noble P, Aluisio FV, Schuck M, Wright J, Lee J. Anatomy, pathologic features and treatment of acetabular labral tears. Clin Orthop 2003; 406: 38-47.

[27] Ganz R, Parvizi J, Beck M, Leunig M, Nötzli H, Siebenrock KA. Femoroacetabular impingement:A cause for early osteoarthritis of the hip. Clin Orthop 2003; 417: 112-20.

[28] Outerbridge RE. The etiology of chondromalacia patellae. J Bone Joint Surg Br 1961; 43-B: 752-7.

[29] Beck M, Leunig M, Parvizi J, Boutier V, Wyss D, Ganz R Anterior femoroacetabular impingement: part II. Midterm results of surgical treatment. Clin Orthop Relat Res 2004; (418): 67-73.

[30] Philippon MJ, Schenker ML. Arthroscopy for the treatment of femoroacetabular impingement in the athlete. Clin Sports Med 2006; 25(2): 299-308, ix.

[31] McCarthy J, Barsoum W, Puri L, Lee JA, Murphy S, Cooke P. The role of hip arthroscopy in the elite athlete. Clin Orthop Relat Res 2003; (406): 71-4.

[32] Mason JB. Acetabular labral tears in the athlete. Clin Sports Med 2001; 20: 779-91.

[33] Bharam S. Labral tears, extra-articular injuries, and hip arthroscopy in the athlete. Clin Sports Med 2006; 25(2): 279-92, ix.

[34] Dorrel JH, Catterall A. The torn acetabular labrnm. J Bone Joint Surg Br 1986; 68: 400-3.

[35] Haene RA, Bradley M, Villar RN. Hip dysplasia and the torn acetabular labrum: an inexact relationship. J Bone Joint Surg $\mathrm{Br}$ 2007; 89(10): 1289-92.

[36] Wiberg G. Studies on dysplastic acetabula and congenital subluxation of the hip joint with special reference to the complications of osteoarthritis. Acta Chir Scand 1939; 83 (Suppl 58): $28-38$

[37] Zaragoza EJ, Beaule PE. Imaging of the painful non-arthritic hip: a practical approach to surgical relevancy. Oper Tech Orthop 2004; 14: $42-8$.

[38] Tonnis D, Heinecke A. Acetabular and femoral anteversion: relationship with osteoarthritis of the hip. J Bone Joint Surg Am 1999; 81: 1747-70.

[39] Tanzer M, Noiseux N. Osseous abnormalities and early osteoarthritis: the role of hip impingement. Clin Orthop Relat Res 2004; 429: 170-7.

[40] Gilmore J. Groin pain in the soccer athlete: fact, fiction, and treatment. Clin Sports Med 1998; 17(4): 787-93, vii.

[41] Klaue K, Durnin CW, Ganz R. The acetabular rim syndrome. A clinical presentation of dysplasia of the hip. J Bone Joint Surg Br 1991; 73: 423-9.

[42] Fitzgerald R. Acetabular labral tears diagnosis and treatment. Clin Orthop 1995; 311: 60-8

[43] Nötzli HP, Wyss TF, Stoecklin CH, Schmid MR, Treiber K, Hodler $\mathrm{J}$. The contour of the femoral head-neck junction as a predictor for the risk of anterior impingement. J Bone Joint Surg Br 2002; 84(4): 556-60.

[44] Reynolds D, Lucas J, Klaue K. Retroversion of the acetabulum. A cause of hip pain. J Bone Joint Surg Br 1999; 81(2): 281-8.

[45] Siebenrock KA, Schoeniger R, Ganz R. Anterior femoroacetabular impingement due to acetabular retroversion. Treatment with periacetabular osteotomy. J Bone Joint Surg Am 2003; 85: 278-86.

[46] Kalberer F, Sierra RJ, Madan SS, Ganz R, Leunig M. Ischial spine projection into the pelvis: a new sign for acetabular retroversion. Clin Orthop Relat Res 2008; 466: 677-83.

[47] Beck M, Kalhor M, Leunig M, Ganz R. Hip morphology influences the pattern of damage to the acetabular cartilage: femoroacetabular impingement as a cause of early osteoarthritis of the hip. J Bone Joint Surg Br 2005; 87: 1012-8.

[48] Ruelle M, Dubois JL. The protrusive malformation and its arthrosic complication. I. Radiological and clinical symptoms. Etiopathogenesis. Rev Rhum Mal Osteoartic 1962 Sep; 29: 476-89.

[49] Wiberg C. Studies on dysplastic acetabula and congenital subluxation of the hip joint. Acta Orthop Scand 1939; 83: 1-5.

[50] Czerny C, Hofmann S, Neuhold A, et al. Lesions of the acetabular labrum: accuracy of MR imaging and MR arthrography in detection and staging. Radiology 1996; 200(1): 225-30.

[51] Edwards DJ, Lomas D, Villar RN. Diagnosis of the painful hip by magnetic resonance imaging and athroscopy. J Bone Joint Surg Br 1995; 77(3): 374-6.

[52] Newberg A, Newman J. Imaging the painful hip. Clin Orthop 2003; 406: 19-28. 
[53] Toomayan GA, Holman WR, Major NM, Kozlowicz SM, Vail TP. Sensitivity of MR arthrography in the evaluation of acetabular labral tears. AJR Am J Roentgenol 2006; 186(2): 449-53.

[54] Chan YS, Lien LC, Hsu HL, et al. Evaluating hip labral tears using magnetic resonance arthrography: a prospective study comparing hip arthroscopy and magnetic resonance arthrography diagnosis. Arthroscopy 2005; 21(10): 1250.

[55] Freedman BA, Potter BK, Dinauer PA, Giuliani JR, Kuklo TR, Murphy KP. Prognostic value of magnetic resonance arthrography for Czerny stage II and III acetabular labral tears. Arthroscopy 2006; 22(7): 742-7.

[56] Lecouvet FE, Vande Berg BC, Malghem J, et al. MR imaging of the acetabular labrum: var.iations in 200 asymptomatic hips. Am J Roentgenol 1996; 167: 1025-8

[57] Cotton A, Boutry N, Demondion X, et al. Acetabular labrum: MRI in asymptomatic volunteers. J Comp Assist Tomogr 1998; 22: 1-7.

[58] Dinauer PA, Murphy KP, Carroll JF. Sublabral sucus at the posterioinferior acetabulum: a potential pitfall in MR arthrography diagnosis of acetabular labral tears. AJR Am Roentgenol 2004; 183: $1745-53$

[59] Petersilge CA, Haque MA, Petersilge WJ, Lewin JS, Liebeman JM, Buly R. Acetabular labral tears: evaluation with MR arthrography. Radiology 1996; 200: 231-5.

[60] Petersen W, Petersen F, Tillmann B. Structure and vascularization of the acetabular labrum with regard to the pathogenesis and healing of labral lesions. Arch Orthop Trauma Surg 2003; 123(6): 283-8.

[61] Hickman JM, Peters CL. Hip pain in the young adult: diagnosis and treatment of disorders of the acetabular labrum and acetabular dysplasia. Am J Orthop 2001; 30(6): 459-67.

[62] Lewis CL, Sahrmann SA. Acetabular labral tears. Phys Ther 2006; 86(1): 110-21.

[63] Smith-Petersen MN. Treatment of malum coxae senilis, old slipped upper femoral epiphysis, intrapelvic protrusion of the acetabulum, and coxa plana by means of acetabuloplasty. J Bone Joint Surg Am 1936 18: 869-80

[64] Ganz R, Gill TJ, Gautier E, Ganz K, Krügel N, Berlemann U. Surgical dislocation of the adult hip: a technique with full access to the femoral head and acetabulum without the risk of avascular necrosis. J Bone Joint Surg Br 2001; 83: 1119-24.

[65] Espinosa N, Rothenfluh DA, Beck M, Ganz R, Leunig M. Treatment of femoro-acetabular impingement: preliminary results of labral refixation. J Bone Joint Surg Am 2006; 88(5): 925-35.

[66] Steadman JR, Rodkey WG, Singleton SB, Britts KK. Microfracture technique for full-thickness chondral defects: technique and clinical results. Oper Tech Orthop1997; 7: 300-4.
[67] Matsusue Y, Yamamuro T, Hama H. Arthroscopic multiple osteochondral transplantation to the chondral defect in the knee associated with anterior cruciate ligament disruption. Arthroscopy 1993; 9: 318-21.

[68] Brittberg $\mathrm{M}$, Lindahl A, Nilsson A, Ohlsson C, Isaksson O, Peterson L. Treatment of deep cartilage defects in the knee with autologous chondrocyte transplantation. N Engl J Med 1994; 331(14): 889-95.

[69] Stalzer S, Wahoff M, Scanlan M, Draovitch P. Rehabilitation after hip arthroscopy. Oper Tech Orthop 2005; 15: 280-9.

[70] Murphy S, Tannast M, Kim YJ, Buly R, Millis MB. Debridement of the adult hip for femoroacetabular impingement: indications and preliminary clinical results. Clin Orthop Relat Res 2004; 429: 17881 .

[71] Beaulé PE, Le Duff MJ, Zaragoza E. Quality of life following femoral head-neck osteochondroplasty for femoroacetabular impingement. J Bone Joint Surg Am 2007; 89: 773-9.

[72] Peters CL, Erickson JA. Treatment of femoro-acetabular impingement with surgical dislocation and débridement in young adults. J Bone Joint Surg Am 2006; 88: 1735-41.

[73] Santori N, Villar RN. Acetabular labral tears: result of arthroscopic partial limbectomy. Arthroscopy 2000; 16: 11-5.

[74] Potter BK, Freedman BA, Andersen RC, Bojescul JA, Kuklo TR, Murphy KP. Correlation of Short Form-36 and disability status with outcomes of arthroscopic acetabular labral debridement. Am J Sports Med 2005; 33: 864-70.

[75] Farjo LA, Glick JM, Sampson TG. Hip arthroscopy for acetabular labral tears. Arthroscopy 1999; 15: 132-7.

[76] O'Leary JA, Berend K, Vail TP. The relationship between diagnosis and outcome in arthroscopy of the hip. Arthroscopy 2001; 17: 181-8.

[77] Byrd JW, Jones KS. Prospective analysis of hip arthroscopy with 2year followup. Arthroscopy 2000; 16: 578-87.

[78] Philippon M, Schenker M, Briggs K, Kuppersmith D. Femoroacetabular impingement in 45 professional athletes: associated pathologies and return to sport following arthroscopic decompression. Knee Surg Sports Traumatol Arthrosc 2007; 15: 908-14.

[79] Bedi A, Chen N, Robertson W, Kelly BT. The management of labral tears and femoroacetabular impingement of the hip in the young, active patient. Arthroscopy 2008; 24(10): 1135-45.

[80] Robertson WJ, Kadrmas WR, Kelly BT. Arthroscopic management of labral tears in the hip: a systematic review of the literature. Clin Orthop Relat Res 2007; 455: 88-92. 